\title{
Impact of the COVID-19 Pandemic on Cancer Treatment
}

\section{Callum Yau ${ }^{1}$, Isaac George Wallbridge ${ }^{1}$, Abhishek Shankar ${ }^{2}$, Deepak Saini ${ }^{3}$, Sachidanand Jee Bharati ${ }^{4}$}

${ }^{1}$ Academic Unit of Medical Education, The University of Sheffield, United Kingdom. ${ }^{2}$ Department of Radiation Oncology, Lady Hardinge Medical College \& SSK Hospital, Delhi, India. ${ }^{3}$ Cancer Control and Prevention Division, Indian Society of Clinical Oncology, Delhi, India. ${ }^{4}$ Department of Oncoanaesthia \& Palliative Medicine, Dr BA Ambedkar Institue Rotary Cancer Hospital, All India Institute of Medical Sciences, India.

\begin{abstract}
The emergence of COVID-19 has now spread across 216 countries and territories worldwide. It has had detrimental effects on the delivery of cancer care and many therapeutic treatments have been paused as a result. Therefore, oncology communities have made two main adaptations so that patients can continue to receive their therapy. The first is to reduce the number of hospital visits and hospitalizations and the second is to prevent anticancer treatment induced complications of COVID-19. Oncologists must consider the published advice available in the absence of international guidelines and as the COVID-19 pandemic continues, approaches to treatment must adjust in order to be safely delivered.
\end{abstract}

Keywords: Cancer - COVID-19- Coronavirus- cancer management

Asian Pac J Cancer Care, 5 (Suppl 1), 247-249

\section{Introduction}

Coronavirus disease (COVID-19) is a respiratory disease caused by Severe Acute Respiratory Syndrome Coronavirus 2 (SARS-CoV-2) and it is spread exponentially by human-to-human transmission [1]. It was first detected in Wuhan, China, in December 2019 and since then it has spread across 216 countries and territories. Currently, as reported by World Health Organization (WHO) on $23^{\text {rd }}$ July, over 15 million people have been infected and over 619,000 people have died from this disease. This disease has had a detrimental impact on the delivery of cancer care worldwide. Cancer patients are reportedly twice more likely to be infected than the general population because of the systemic immunocompromised state caused by the malignancy and anticancer treatments [2-3]. Another likely factor is the frequency of hospital visits by these patients. The outcome of COVID- 19 has been significantly worse and 39\% cases have resulted in death or ICU admission, in comparison to $8 \%$ found in the general population $(p=0.0003)$. The risk of severe events is also higher amongst those patients who have undergone curative treatment within the past month [1].
Submission Date: 07/24/2020 Acceptance Date: 10/04/2020
To date, there have been no official international guidelines for the management of cancer care and as countries have started to ease their lockdown restriction, numbers of new cases have started to rise.

Current changes to Cancer treatment caused by the COVID-19 pandemic

Across all cancer treatment centres, treatment regimens and care provision have been adapted for two reasons, one, to minimise the number of hospital visits and hospitalizations and second, to prevent anticancer treatment induced complications of COVID-19 [4].

\section{Changes due to minimisation of hospital visits and hospitalization}

Issues relating to social distancing lockdowns and curfews have created major long-term issues for curative and palliative oncological care [5]. Patients need to be predominantly managed outside of hospital/treatment centres to minimise infection risk leading to issues with the provision of timely treatments, continuity of care and

Corresponding Author:

Dr. Callum Yau

Academic Unit of Medical Education, The University of Sheffield, United Kingdom.

Email: cyau2@sheffield.ac.uk 
access to clinical trials most of which are now closed to recruitment [4-6]. Remote interview through video or telephone link to hold outpatient clinics has become routine practice in situations where the risk of infection created by attending hospital has outweighed the benefits of face to face discussion [7]. Indeed, precautions can be put in place to reduce the number of visits, however most hospital admissions are the cause of medical emergencies [8]. Other measures to reduce infection risk to patients include Home deliveries of oral medicines, Local availability of clinical testing, Remote counselling and rationalisation of investigations [5].

Changes in anticancer treatment undertaken to prevent complications of COVID-19

Changes undertaken with regards to treatment regimen include conversion of Intra Venous (IV) therapy to oral. Subcutaneous injection can be used where possible - reducing need for visitation to clinical environments; Swapping cytotoxic chemotherapy for less-toxic (monotherapy) treatments to decrease risk of complications and therefore hospital admissions and pausing therapies once a stable disease state (or better) is achieved reducing the need for hospital admission [4].

The pandemic has led to many issues with regard to anticancer treatment, clinicians have had to balance the weight of risk and morbidity from COVID-19 and the magnitude of benefit from intended therapeutic treatment [9]. This situation has also led to the cancellation of non-emergency surgery, including oncological surgeries, with them being replaced by radiotherapy [4].

\section{Future Impact of Covid-19 on Cancer Care}

As the COVID-19 pandemic continues, so too will the treatment approaches taken by centres need to adjust. In the following section we have identified a number of key future issues with cancer care:

\section{Surgical prioritisation}

Due to the uncertainty surrounding how long the pandemic will last, surgical prioritisation will become a growing issue [10]. In consideration of which procedures should be prioritised, certain patient groups may be more appropriate for having surgical delays (e.g., early asymptomatic small breast cancer tumors detected on routine screening mammograms) [10]. The issue of surgical capacity arises due to the reduction of hospital beds, as ventilators and Intensive Care Unit (ICU) beds are used to provide critical care for COVID-19 patients and patients being reluctant to undergo elective surgery after hearing reports of others catching COVID-19 in the hospital environment [11]. A potential solution is performing surgery in "cancer hubs", surgical units either adapted or created in areas kept free of COVID-19. This would create more capacity and reduce back-log of semi-elective surgery [11].

\section{Lack of identification}

There is serious concern that the number of patients presenting with more advanced cancers will increase.
Wales, Scotland and Northern Ireland have all cancelled their screening programmes leading to less early detection [11]. Furthermore, one in five cancers are picked up on emergency hospital admissions and with Accident and Emergency (A\&E) admissions rates falling since the start of the pandemic, there are also concerns regarding the delayed presentation of a number of cancers cases which would have been picked up earlier if patients had attended A\&E [11].

\section{Chemotherapy prioritisation}

Issues regarding the consideration of the benefits of chemotherapy over risk of infection with COVID-19 and increased risk of developing complications will continue. In addition, It is anticipated that the COVID-19 pandemic could lead to shortages in the supply of a number of chemotherapy drugs, as of 21 March 2020 the US Food and Drug Administration shortage list included 26 oncology medications [10]. Solutions to this issue include Multidisciplinary team (MDT) approach of communication and transparency between stakeholders, suppliers and health organisations, as well as adaptation with the use of alternate therapies such as radiotherapy [10].

\section{Radiotherapy treatment programmes}

Radiotherapy has been identified as a method to replace or delay other treatments that have higher COVID-19 infection risks [9]. Reports have suggested that under strict guidelines and preventive measure radiotherapy services can continue throughout the pandemic [12-13]. However, the service may become overloaded due to the backlog of patients already waiting for surgery. Furthermore, some radiotherapy programmes require daily sessions and that interruption is clinically unacceptable [14]. Therefore, patients who are undergoing treatment must continue and any additional cases must be considered on an individual basis.

In conclusion, COVID-19 is having a detrimental effect on cancer patients worldwide. focussing on the two key areas of adaptation in delivery of cancer care that have resulted from this pandemic can improve outcome. Oncologist should look for recent guidance published by oncology societies or organizations and collated the information to offer further advice on future issues arising from the COVID-19 pandemic. With the continually increasing number of cases worldwide, it is imperative that more research is performed to understand the implications of this virus with regards to anti-cancer therapies and that health organisations consider alternative methods to deal with the backlog of semi-elective surgeries, such as "Cancer hubs", so that cancer patients can continue to receive the best evidence informed treatments. 


\section{References}

1. Liang W, Guan W, Chen R, Wang W, Li J, Xu K, Li C, Ai Q, Lu W, Liang H, Li S, He J. Cancer patients in SARSCoV-2 infection: a nationwide analysis in China. The Lancet Oncology. 2020 03;21(3):335-337. https://doi.org/10.1016/ s1470-2045(20)30096-6

2. Shankar A, Saini D, Roy S, Mosavi Jarrahi A, Chakraborty A, Bharti SJ, Taghizadeh-Hesary F. Cancer Care Delivery Challenges Amidst Coronavirus Disease - 19 (COVID-19) Outbreak: Specific Precautions for Cancer Patients and Cancer Care Providers to Prevent Spread. Asian Pacific Journal of Cancer Prevention. 202003 01;21(3):569-573. https://doi.org/10.31557/apjcp.2020.21.3.569

3. Shankar A, Saini D, Bhandari R, Bharati S, Kumar S, Yadav $\mathrm{G}$, et al. Lung cancer management challenges amidst COVID-19 pandemic: hope lives here. Lung Cancer Manag. 2020:10.2217/lmt-020-0012.

4. van de Haar J, Hoes LR, Coles CE, Seamon K, Fröhling S, Jäger D, Valenza F, de Braud F, De Petris L, Bergh J, Ernberg I, Besse B, Barlesi F, Garralda E, Piris-Giménez A, Baumann M, Apolone G, Soria JC, Tabernero J, Caldas C, Voest EE. Caring for patients with cancer in the COVID-19 era. Nature Medicine. 202004 16;26(5):665-671. https:// doi.org/10.1038/s41591-020-0874-8

5. Spicer J, Chamberlain C, Papa S. Provision of cancer care during the COVID-19 pandemic. Nature Reviews Clinical Oncology. 2020;17(6):329-31.

6. NHS E. Clinical guide for the management of non-coronavirus patients requiring acute treatment 2020 [updated March 23; cited 2020 July 23]. Available from: https://www.england. nhs.uk/coronavirus/wp-content/uploads/sites/52/2020/03/ specialty-guide-acute-treatment-cancer-23-march-2020.pdf.

7. NICE. The UK National Institute of Health and Care Excellence - COVID-19 rapid guideline: delivery of systemic anticancer treatments 2020 [updated April 27; cited 2020 July 23]. Available from: https://www.nice.org. uk/guidance/ng161.

8. Numico G, Cristofano A, Mozzicafreddo A, Cursio OE, Franco P, Courthod G, Trogu A, Malossi A, Cucchi M, Sirotovà Z, Alvaro MR, Stella A, Grasso F, Spinazzé S, Silvestris N. Hospital Admission of Cancer Patients: Avoidable Practice or Necessary Care?. Santini D. PLOS ONE. 201503 26;10(3):e0120827. https://doi.org/10.1371/ journal.pone. 0120827

9. Hanna TP, Evans GA, Booth CM. Cancer, COVID-19 and the precautionary principle: prioritizing treatment during a global pandemic. Nature Reviews Clinical Oncology. 2020 04 02;17(5):268-270. https://doi.org/10.1038/s41571-020$0362-6$

10. Al-Shamsi HO, Alhazzani W, Alhuraiji A, Coomes EA, Chemaly RF, Almuhanna M, Wolff RA, Ibrahim NK, Chua ML, Hotte SJ, Meyers BM, Elfiki T, Curigliano G, Eng C, Grothey A, Xie C. A Practical Approach to the Management of Cancer Patients During the Novel Coronavirus Disease 2019 ( COVID -19) Pandemic: An International Collaborative Group. The Oncologist. 202004 27;25(6). https://doi.org/10.1634/theoncologist.2020-0213

11. Richards M, Anderson M, Carter P, Ebert BL, Mossialos E. The impact of the COVID-19 pandemic on cancer care. Nature Cancer. 202005 20;1(6):565-567. https://doi. org/10.1038/s43018-020-0074-y

12. Xie C, Wang X, Liu H, Bao Z, Yu J, Zhong Y, et al. Infection Control of 2019 Novel Corona Virus Disease (COVID-19) in Cancer Patients undergoing Radiotherapy in Wuhan. medRxiv. 2020:2020.03.21.20037051.
13. Krengli M, Ferrara E, Mastroleo F, Brambilla M, Ricardi U. Running a Radiation Oncology Department at the Time of Coronavirus: An Italian Experience. Advances in Radiation Oncology. 2020 07;5(4):527-530. https://doi.org/10.1016/j. adro.2020.03.003

14. Mukherjee R, Back M, Lu J, Shakespeare T, Wynne C. Hiding in the Bunker: Challenges for a radiation oncology department operating in the Severe Acute Respiratory Syndrome outbreak. Australasian Radiology. 2003 06;47(2):143-145. https://doi.org/10.1046/j.00048461.2003.01165.x

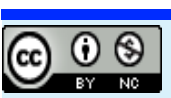

This work is licensed under a Creative Commons AttributionNon Commercial 4.0 International License. 